\title{
Safety Assessment Research of Aqueduct in the Irrigation Area
}

\author{
Lei XU \\ China Irrigation and Drainage Development Center \\ Beijing, China \\ e-mail: bhhbx@126.com \\ Yanli FAN \\ China Irrigation and Drainage Development Center \\ Beijing, China \\ e-mail: 327296206@qq.com
}

\author{
Mingqi CHANG \\ China Irrigation and Drainage Development Center \\ Beijing, China \\ e-mail: cmq93@163.com
}

\author{
Liguo LU \\ Ningxia Institute of Water Resource Research \\ Yinchuan, China
}

\author{
Jingchao GU \\ Ningxia Institute of Water Resource Research \\ Yinchuan, China
}

\begin{abstract}
Due to natural conditions, work environment, maintenance management and other factors, in the course of the use, the aqueduct hydraulic structures may appear material aging, structural damage, performance and other situations, and bring hidden dangers to the safe operation. Aimed at the insufficient of the research status and the existing problems, according to structure characteristics of the aqueduct, combined with theoretical research and development trend, the paper proposed a method of fuzzy comprehensive evaluation analytic hierarchy to carry out the aqueduct hydraulic structures safety assessment. The method divided the aqueduct hydraulic buildings into three level indicators and four layers. Analytic hierarchy process is used in the weights determine of many influence factors, fuzzy comprehensive evaluation method is used in the multistage evaluation of the many influence factors, and finally with an example to show how the method was used in practical application.
\end{abstract}

Keywords-aqueduct; safety assessment; fuzzy comprehensive evaluation analytic hierarchy process

\section{INTRODUCTION}

As a kind of widely used hydraulic cross building, aqueduct plays an important role in irrigation water distribution, drainage and river diversion. Since the 1960s, lot kinds of light structure and large span arch aqueduct were widely developed in construction and reformation of large and middle irrigation district in China. These structures were used to solve the problems of irrigation water diversion, and promote the development of rural water conservancy.

However, by the interaction of the natural environment and the use condition, the functions of various buildings were gradually weakened with the elapse of time. The weak of the functions also included the aqueduct hydraulic structures. This appearance may cause many aging projects to be repaired not in time, and do not function well.
Therefore, how to assess the safety of aqueduct scientifically and effectively has become more and more important.

\section{RESEARCH DYNAMIC}

In order to solve the problems of aging and diseases, many scholars both domestic and abroad have carried out a lot positive and beneficial researches. K. S. Wang, P. Leger, etc.[1], did researches on building models for fatigue crack growth problem; Seje Carlsten, Sam Johansson, V. K. Karastathis, etc. [2], made studies for indicating internal erosion in embankment dams; CH. Maierthofer, etc. [3],did researches on non-destructive investigation of sluice by using radar and ultrasonic impulse echo. In domestic, Liu Hua-xin [4] did researches on aging problem of hydraulic structures; Li Yan-dong [5] focused on the analysis of safety review evaluation results in Wangjiaba gate hydraulic building; Li Yan, Cui Zhen-ming, etc. [6], made studies on safety evaluation of hydraulic structures; based on the principle of system analysis, Tao Jia-liang [7] took discussion on aging degree evaluation for hydraulic structures. However, at present, the aging and safety evaluation methods of hydraulic structures are mostly extended from the engineering buildings, the way to health diagnosis and safety assessment for hydraulic structures is still weak. Especially, in China, although the number of aqueduct is huge, the theory for evaluation is not mature yet, and lack of operational, simple and practical [1-19].

Based on these conditions, through the combination of theoretical analysis and example calculation, the paper preliminary discussed the safety evaluation index, methods and the technological process on safety assessment of aqueduct in the irrigation area, so as to provide useful references for the safety evaluation of canal system in irrigation district. 


\section{EVALUATION SYSTEM CONSTRUCTION AND ANALYSIS}

\section{A. Evaluation Hierarchy Construction}

As water conveyance structure, the water flow characteristic of the aqueduct is from upstream to downstream. The characteristic of the aqueduct structure is composed by upper bearing structure, middle support transmission structure and lower base. Based on this feature, by the principle of the operational and credibility characteristics, the evaluation hierarchy was constructed. The hierarchy relation of aqueduct safety assessment was shown below.

TABLEI. HiERARCHY RELATION OF AQUEDUCT SAFETy ASSESSMENT

\begin{tabular}{|c|c|c|}
\hline \multirow{5}{*}{$\begin{array}{l}\text { Hydraulic } \\
\text { condition }\end{array}$} & \multirow{2}{*}{ Flow pattern } & In-flow \\
\hline & & Out-flow \\
\hline & \multirow{2}{*}{ Water level } & In-flow \\
\hline & & Out-flow \\
\hline & $\begin{array}{c}\text { Water flow } \\
\text { amantity }\end{array}$ & \\
\hline \multirow{4}{*}{$\begin{array}{c}\text { Structural } \\
\text { deformation }\end{array}$} & Aqueduct body & Deflection \\
\hline & Supporting pier & Top horizontal displacement \\
\hline & \multirow{2}{*}{ Transition section } & In-flow \\
\hline & & Out-flow \\
\hline \multirow{9}{*}{$\begin{array}{l}\text { Structural } \\
\text { damage }\end{array}$} & \multirow{3}{*}{ Aqueduct body } & Surface damage \\
\hline & & Steel exposed, corrosion \\
\hline & & Crack and leakage \\
\hline & \multirow{3}{*}{ Supporting pier } & Surface damage \\
\hline & & Steel exposed, corrosion \\
\hline & & Crack and leakage \\
\hline & \multicolumn{2}{|l|}{ Water-seal } \\
\hline & \multirow{2}{*}{ Transition section } & In-flow \\
\hline & & Out-flow \\
\hline \multirow{2}{*}{ Basics } & Foundation & \\
\hline & Understructure & \\
\hline
\end{tabular}

\section{B. Index Grade Classification}

According to the above level structure relationship table, the safety evaluation index of the aqueduct was divided into third grade and four level, including objective level $P$, principal level $C$, index level $N$ and sub-index level $U$. Under the objective level $P$, the principal level $C$ contained 4 first class indicators: hydraulic condition, structural deformation, structural damage, foundation. Under the 4 first class indicators, there were 12 second level indicators composed indexes $N$. Under the second level indicators, there were 16 third level indicators composed indexes $U$. In addition to the above indicators, vertical displacement, horizontal displacement, carbonization depth, damaged area, concrete grade, etc. also can be used as the third level indicators. These indicators formed a multi-layer and complex index system.

\section{Index Weight Determination}

When calculating the index weight in table 1 by using the analytic hierarchy process, the basic calculation problem is to quantify judgment the indicators by the scale from 1-9. The judgment matrix $A$ was built with the same layer of the correlation between the two indicators. If the number of the influence factor was $n$, then judgment matrix $A$ will be defined as an $n$ order judgment matrix. According to the principle of matrix eigenvalue, $n$ was a characteristic root of matrix $A$. After normalized the parameters of $\lambda_{\max }$ and $W$, the weight vector of each indicators were formed [20-22].

Calculation of largest eigenvalue $\lambda_{\max }$ and characteristic vector $W$ :

1. Characteristic vector $\mathrm{W}$

The characteristic vector $W$ was calculated by two steps, first geometric averaging each column vector of matrix $A$, and then normalizing these vectors.

$$
\begin{aligned}
& \omega_{i}=\frac{\left(\prod_{j=1}^{m} a_{i j}\right)^{1 / m}}{\sum_{k=1}^{m}\left(\prod_{j=1}^{m} a_{k j}\right) 1 / m} \\
& (i, j, k=1,2, \ldots \ldots m)
\end{aligned}
$$

2. $\lambda_{\max }$

$$
\lambda_{\max }=\frac{1}{m} \sum_{i=1}^{m} \frac{(A W)_{i}}{\omega_{i}}=\frac{1}{m} \sum_{i=1}^{m} \frac{\sum_{j=1}^{m} a_{i j} \omega_{j}}{\omega_{i}}
$$

$(A W)_{i}$ means the component of vector $A W$ Consistency check

$$
\text { C.I. }=\frac{\lambda_{\max }-n}{n-1}
$$

$n$ means the order of judgment matrix

Based on the order of the matrix, the average random consistency index R.I. can be got from table 2 .

TABLEII. AVERAGE RANDOM CONSISTENCY INDEX R.I.

\begin{tabular}{|c|c|c|c|c|c|c|c|c|}
\hline$n$ & 1 & 2 & 3 & 4 & 5 & 6 & 7 & 8 \\
\hline$R . I .$. & 0 & 0 & 0.53 & 0.9 & 1.12 & 1.26 & 136 & 1.41 \\
\hline$n$ & 9 & 10 & 11 & 12 & 13 & 14 & 15 & \\
\hline$R . I .$. & 1.46 & 1.49 & 1.52 & 154 & 156 & 156 & 159 & \\
\hline
\end{tabular}


TABLEIII. WEIGHT TABLE of AQUEDUCT SAFETy AsSESSMENT

\begin{tabular}{|c|c|c|c|c|c|}
\hline \multicolumn{6}{|c|}{ Evaluation index } \\
\hline First level indicator & Weight A & Second level indicator & Weight $A_{I}$ & Third level indicator & Weight $A_{11}$ \\
\hline \multirow{5}{*}{ Hydraulic condition } & \multirow{5}{*}{0.1} & \multirow{2}{*}{ Flow pattern } & \multirow{2}{*}{0.2605} & In-flow & 0.5 \\
\hline & & & & Out-flow & 0.5 \\
\hline & & \multirow{2}{*}{ Water level } & \multirow{2}{*}{0.1061} & In-flow & 0.5 \\
\hline & & & & Out-flow & 0.5 \\
\hline & & Water flow quantity & 0.6334 & & 1.0 \\
\hline \multirow{4}{*}{ Structural deformation } & \multirow{4}{*}{0.4} & Aqueduct body & 0.2828 & Deflection & 1.0 \\
\hline & & Supporting pier & 0.6434 & Top horizontal displacement & 1.0 \\
\hline & & \multirow{2}{*}{ Transition section } & \multirow{2}{*}{0.0738} & In-flow & 0.5 \\
\hline & & & & Out-flow & 0.5 \\
\hline \multirow{9}{*}{ Structural damage } & \multirow{9}{*}{0.2} & \multirow{3}{*}{ Aqueduct body } & \multirow{3}{*}{0.4301} & Surface damage & \\
\hline & & & & Steel exposed corrosion & 0.4545 \\
\hline & & & & Crack and leakage & 0.4545 \\
\hline & & \multirow{3}{*}{ Supporting pier } & \multirow{3}{*}{0.4301} & Surface damage & \\
\hline & & & & Steel exposed corrosion & 0.4545 \\
\hline & & & & Crack and leakage & 0.4545 \\
\hline & & Water-seal & 0.0892 & & 1.0 \\
\hline & & \multirow{2}{*}{ Transition section } & \multirow{2}{*}{0.0506} & In-flow & 0.5 \\
\hline & & & & Out-flow & 0.5 \\
\hline \multirow{2}{*}{ Basics } & \multirow{2}{*}{0.3} & Foundation & 0.4 & & 1.0 \\
\hline & & Understructure & 0.6 & & 1.0 \\
\hline
\end{tabular}

Consistency ratio $C . R$

$$
\text { C.R. }=\text { C.I./R.I. }
$$

The smaller the C.R. is, the better the consistency of the judgment matrix. It is usually considered, when C.R. $<0.1$ the decision maker's judgment is consistent, the result can be accepted. Otherwise, it needed to be adjusted till satisfy.

\section{Fuzzy Comprehensive Evaluation [23]}

\section{1) Membership function determine:}

Semi trapezoidal distribution membership function is adopted in this study to divide each indicator into 2 types. One type was the positive effect indicator (the bigger the better); another type was negative effect indicator (the smaller the better).

2)Fuzzy matrix determine:
Taken the standardized processed data into membership functions, then the $m \times n$ order matrix would be got. 3) Fuzzy relation operation:

According to the weight vector of the objective level and the principal level, the comprehensive evaluation was made to these two levels separately.

\section{EXAMPLE}

\section{A. General Situation}

The total length of an aqueduct was $114 \mathrm{~m}$, and it had 13 spans. The maximum span length was $10 \mathrm{~m}$; the length of in-flow transition section was $9.3 \mathrm{~m}$, and $8 \mathrm{~m}$ for the length of out-flow transition section. The design flow of the aqueduct was $2.4 \mathrm{~m}^{3} / \mathrm{s}$; the enlarged flow was $2.7 \mathrm{~m}^{3} / \mathrm{s}$; the longitudinal gradient was $1 / 5000$. The width of this aqueduct was $1.55 \mathrm{~m}$, and the arc radius was $0.65 \mathrm{~m}$. The structure of the aqueduct was prefabricated $4 \mathrm{~cm}$ thick wire mesh shell. 


\section{B. Evaluation Process}

TABLEIV. THE MEMBERSHIP DEGREE OF THE THIRD LEVEL INDICATORS

\begin{tabular}{|c|c|c|c|}
\hline \multicolumn{3}{|c|}{ Membership degree } \\
\hline$A$ & $B$ & $C$ & 0.2 \\
\hline 0 & 0.8 & 0.2 & 0 \\
\hline 0 & 0.8 & 0 & 0 \\
\hline 0 & 1 & 0.1 & 0 \\
\hline 0 & 0.9 & 0.2 & 0 \\
\hline 0 & 0.8 & 0.3 & 0 \\
\hline 0 & 0.7 & 0.4 & 0 \\
\hline 0 & 0.6 & 0.21 & 0 \\
\hline 0 & 0.79 & 0.2 & 0 \\
\hline 0 & 0.8 & 0.7 & 0 \\
\hline 0 & 0.3 & 0.8 & 0 \\
\hline 0 & 0.2 & 0.8 & 0.23 \\
\hline 0 & 0.2 & 1 & 0 \\
\hline 0 & 0 & 0.6 & 0 \\
\hline 0 & 0.4 & 0.77 & 0 \\
\hline
\end{tabular}

\section{1)Membership degree matrix calculation:}

Took the measured data and the standard data into the membership function, the membership degree matrix, which used to appraise the safety degree of the aqueduct, could be got. The details of the membership degree the third level indicators were shown in table 4.

2)Evaluation result:

(1) Third level comprehensive evaluation

$$
\begin{aligned}
& \boldsymbol{B}_{i k}=\boldsymbol{A}_{i k} \bullet \boldsymbol{R}_{i k} \\
& \quad(i=1,2,3,4 ; k=1,2 \ldots \ldots ; k)
\end{aligned}
$$

According to (5), the comprehensive judgment was made to the three level indicators, and the results were shown below:

- Flow pattern fuzzy comprehensive evaluation: The maximum membership degree was $B$, and the flow pattern was basically stable.

- Water level fuzzy comprehensive evaluation: The maximum membership degree was $\mathrm{B}$, and the flow pattern was basically stable.

- Water flow quantity fuzzy comprehensive evaluation: The maximum membership degree was $\mathrm{B}$, and the water flow quantity was basically stable.

- Aqueduct body structural deformation fuzzy comprehensive evaluation: The maximum membership degree was $\mathrm{B}$, and the situation of the aqueduct body structural was basically normal.

- Supporting pier deformation fuzzy comprehensive evaluation: The maximum membership degree was $\mathrm{B}$, and the situation of the supporting pier deformation was basically normal.

- Transition section deformation fuzzy comprehensive evaluation: The maximum membership degree was $\mathrm{B}$, and the situation of the transition section deformation was basically normal.

- Aqueduct body structural damage fuzzy comprehensive evaluation: The maximum membership degree was $\mathrm{C}$, and the situation of the aqueduct body structural was abnormal.

- Supporting pier structure damage fuzzy comprehensive evaluation: The maximum membership degree was $\mathrm{C}$, and the situation of the Supporting pier structure was abnormal.

- Water-seal structure damage fuzzy comprehensive evaluation: The maximum membership degree was $\mathrm{C}$, and the situation of the water-seal structure was abnormal.

- Transition section damage fuzzy comprehensive evaluation: The maximum membership degree was $\mathrm{B}$, and the situation of the transition section structure was basically normal.

- Foundation fuzzy comprehensive evaluation: The maximum membership degree was $\mathrm{B}$, and the situation of the foundation was basically normal. 
- Understructure fuzzy comprehensive evaluation: The maximum membership degree was $\mathrm{B}$, and the situation of the understructure was basically normal.

(2) Second level comprehensive evaluation

The indicators (bl b2 b3 b4) of the third level ( $U$ level) fuzzy comprehensive evaluation index were used as the foundation to form the evaluation matrix $R_{i}$ of the second level ( $N$ level).Then the equation was got as below.

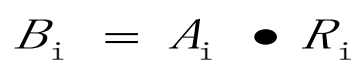

$$
(i=1,2,3,4)
$$

According to (6), the comprehensive judgment was made to the second level indicators, and the results were shown below:

- Hydraulic condition fuzzy comprehensive evaluation: The maximum membership degree was $\mathrm{B}$, and the situation of the hydraulic condition was basically normal.

- Structural deformation fuzzy comprehensive evaluation: The maximum membership degree was $\mathrm{B}$, and the situation of the structural deformation was basically normal.

- Structural damage fuzzy comprehensive evaluation: The maximum membership degree was $\mathrm{C}$, and the situation of the structural damage was abnormal.

- Basics fuzzy comprehensive evaluation: The maximum membership degree was $\mathrm{B}$, and the situation of the basics was basically normal.

(3) First level comprehensive evaluation:

$$
B=A_{\mathrm{i}} \bullet R
$$

According to (7), the maximum membership degree was $B$, and the situation of the aqueduct was basically normal.

\section{CONCLUSIONS}

The advantages of using this method to evaluate the aqueduct were simple process and low cost. Meanwhile, the measured results showed that, using this method to make the evaluation of the aqueduct can also meet the requirements of accurate degree. This method can be used practically and effectively especially for the large scaled work. But the limitation of this method was that can only be used in current situation assessment, and lack in forecast. This need to be improved in the future research work.

\section{REFERENCES}

[1] K.S.Wang, S.T.Chang, Y.C.Shen. Dynamic reliability models for fatigue crack growth problem [J]. Engineering fracture mechanics, 1996, 54(4):543-556.

[2] Seje Carlsten, Sam Johansson, Anders Worman. Radar techniques for indicating internal erosion in embankment dams [J]. Journal of Applied Geophysics, 1995, 33(1-3):143-156.
[3] CH.Maierthofer, M.Krause, H.Wiggenhauser. Non-destructive investigation of sluice using radar and ultrasonic impulse echo [J]. NDT\&E international, 1998, 31(6):421-427.

[4] LIU Hua-xin. Aging Problem of Hydraulic Structures [J]. Henan Water Resources \& South-to-North Water Diversion, 2012, (14):151-152.

[5] LI Yan-dong. Analysis of Safety Review Evaluation Results in Wangjiaba Gate Hydraulic Building [J]. Water Resources Development and Management, 2014, (9): 57-60.

[6] LI Yan, CUI Zhen-ming, etc. Safety Evaluation of Hydraulic Structures Based on Grey Correlation Degree [J]. Low Temperature Architecture Technology, 2014, (10):139-141.

[7] TAO Jia-liang. Brief Discussion on Aging Degree Evaluation for Hydraulic Structures [J]. Heilongiiang Science and Technology of Water Conservancy, 2014, 42(6):20-22.

[8] CAO Shuang-yin, QIU Hong-xing, etc. Structure reliability appraisal and strengthening technology [M]. Beijing: China Water\&Power Press, 2002.

[9] HU Guo-wei. Analysis of Hydraulic Concrete Quality Nondestructive Testing Technology [J]. Henan Water Resources \& South-to-North Water Diversion, 2013, (24):18-19.

[10] ZHONG Xing-wu, CHEN Zheng-shi, etc. Application of Nondestructive Testing Technology in Concrete Engineering [J]. Sichuan Water Resources, 2015, (4):16-17.

[11] WEI Xin, CHEN Chen, etc. Development and Engineering Application of Nondestructive Testing Technology of Concrete [J]. Education Teaching Forum, 2015, (5):108-109.

[12] Therese P.McAllister, Bruce R.Ellingwood. Evaluation of crack growth in miter gate weldments using stochastic fracture mechanics [J]. Structural Safety, 2001, 23(4):445-465.

[13] Allen C.Estes, Dan M.Frangopol, Stauat D.Foltz. Updating reliability of steel miter gates on locks and dams using visual inspection results [J].Engineering Structures, 2004, 26(3):319-333.

[14] V.K.Karastathis, P.N.Karmis, etc. Geophysical methods contributing to the testing of concrete dams Application at Marathon Dam [J].Journal of Applied Geophysics, 2002, 50(3):247-260.

[15] LIU Shang-kun. Health Diagnosis and Safety Evaluation Research of Reinforced Concrete Aqueduct Structure [D]. Yangling: Northwest A \& F University, 2015:1-2.

[16] CAO Jie-xiong. Analysis of Safety Evaluation Method Based on the Detection of an Aqueduct [J]. Low Temperature Architecture Technology, 2015, (3):82-83.

[17] XIA Fu-zhou, CHEN Dong-liang, etc. Research on the Reliability of Aqueducts Based on Fuzzy Comprehensive Evaluation and Variable Weight Method [J]. China Rural Water and Hydropower, 2012, (9):96-100

[18] HUANG Chun-hua, YUAN Ming-dao, etc. Problems in Aqueduct Safety Evaluation [J]. GUANGDONG WATER RESOURCES AND HYDROPOWER, 2014(5):11-13.

[19] WANG Meng-ya, XIA Fu-zhou. Aging assessment of aqueduct structures based on extension method [J]. Engineering Journal of Wuhan University, 2014, 47(2): 211-216.

[20] DENG Xue, LI Jia-ming, ect. Analysis and Application Research on Weight Calculation Method of Analytic Hierarchy Process [J]. MATHEMATICS IN PRACTICE AND THEORY, 2012, 42(7): 93-100.

[21] YU Zhi-gang. Application of grey relational analysis method in water conservancy project risk assessment [J]. Henan Water Resources \& South-to-North Water Diversion, 2012, (14):67-68.

[22] LI Kui-ran, LI Huan, etc. Research on the Index System of Risk Evaluation in Hydraulic Engineering Based on Analytical Hierarchy Process [J]. ECONOMIC RESEARCH GUIDE, 2013, (30):192-194.

[23] WANG Pei-zhuang. Fuzzy Set Theory and Its Application [M]. Shanghai: Shanghai science and Technology Press, 1983. 